

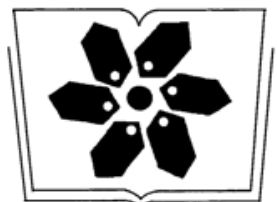

中国科学院科学出版基金资助出版
生 态 学 报

(SHENGTAI XUEBAO)

第 33 卷第 19 期 2013 年 10 月 (半月刊)

中国生态学学会 2013 年学术年会专辑 卷首语

生态系统服务研究文献现状及不同研究方向评述。 马凤娇, 刘金铜, A. Egrinya Eneji (5963) 非人灵长类性打摚行为研究进展 杨斌,王程亮,纪维红,等 (5973) 密度制约效应对啮齿动物繁殖的影响 . 韩群花, 郭 聪, 张美文 (5981) 食物链长度远因与近因研究进展综述 王玉玉,徐军,雷光春 (5990) $\mathrm{AM}$ 真菌在植物病虫害生物防治中的作用机制 罗巧玉，王晓娟，李媛媛，等 (5997) 保护性耕作对农田碳、氮效应的影响研究进展 . 薛建福, 赵 荃金, Shadrack Batsile Dikgwatlhe, 等 (6006) 圈养大熊猫野化培训期的生境选择特征 张明春,黄炎,李德生,等 (6014) 利用红外照相技术分析野生白冠长尾雉活动节律及时间分配 赵玉泽, 王志臣,徐基良,等 (6021) 风速和持续时间对树麻雀能量收支的影响 杨志宏, 吴庆明, 董海燕, 等 (6028) 白马雪山自然保护区灰头小舀鼠的巢址特征 李艳红, 关进科,黎大勇,等 (6035) 生境片段化对千岛湖岛屿上黄足厚结猛蚁遗传多样性的影响 罗媛媛, 刘金亮, 黄杰灵, 等 (6041) 基于 $28 \mathrm{~S}$, COI 和 Cytb 基因序列的薜荔和爱玉子传粉小蜂分子遗传关系研究

吴文珊, 陈友铃, 孙伶俐, 等 (6049) 高榕榕果内 Eupristina 属两种榕小蜂的遗传进化关系 陈友铃, 孙伶例, 武蕾蕾, 等 $(6058)$ 镉胁迫下杞柳对金属元素的吸收及其根系形态构型特征 王树风, 施翔, 孙海菁, 等 (6065) 邻苯二甲酸对萝卜种子萌发、幼苗叶片膜脂过氧化及渗透调节物质的影响

杨延杰, 王晓伟, 赵 康, 等 (6074)

极端干旱区多枝柽柳幼苗对人工水分干扰的形态及生理响应 马晓东, 王明慧, 李卫红, 等 (6081) 贝壳砂生境酸柬叶片光合生理参数的水分响应特征..... 王荣荣,夏江宝,杨吉华,等 (6088) 陶粒覆盖对土壤水分、植物光合作用及生长状况的影响..... 谭雪红, 郭小平, 赵廷宁 (6097) 不同林龄短枝木麻黄小枝单宁含量及养分再吸收动态..... 叶功富, 张尚炬, 张立华,等 (6107)

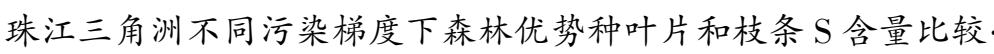
裴男才, 陈步峰, 邹志谨, 等 (6114) $\mathrm{AM}$ 真菌和磷对小马安羊蹄甲幼苗生长的影响 宋成军,曲来叶,马克明, 等 (6121) 盐氮处理下盐地碱蓬种子成熟过程中的离子积累和种子萌发特性............... 周家超,付婷婷, 赵维维,等 (6129) $\mathrm{CO}_{2}$ 浓度升高条件下内生真菌感染对宿主植物的生理生态影响 师志冰, 周 勇, 李 夏, 等 $(6135)$ 预处理方式对香蒲和芦苇种子萌发的影响 孟 焕,王雪宏,佟守正,等 (6142) 镉在土壤-金丝垂柳系统中的迁移特征 雯, 魏 虹, 孙晓灿, 等 (6147) 马尾松人工林近自然化改造对植物自然更新及物种多样性的影响........ 罗应华,孙冬婧,林建勇,等 (6154) 濒危海草贝克喜盐草的种群动态及土壤种子库 以广西珍珠湾为例……

邱广龙,范航清,李宗善,等 (6163)

毛乌素沙地南缘沙丘生物结皮对凝结水形成和蒸发的影响 尹瑞平, 吴永胜, 张 欣, 等 (6173) 塔里木河上游灰胡杨种群生活史特征与空间分布格局…… 韩 路, 席琳乔, 王家强, 等 (6181)

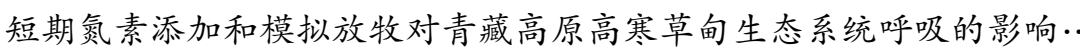
宗宁, 石培礼, 蔣 婧, 等 (6191) 松嫩平原微地形下土壤水盐与植物群落分布的关系 杨 帆,王志春,王云贺,等 (6202) 
广州大夫山雨季林内外空气 TSP 和 $\mathrm{PM}_{2.5}$ 浓度及水溶性离子特征 马鞍列岛岩礁生境鱼类群落结构时空格局…… 黄海细纹狮子鱼种群特征的年际变化. 三种温带森林大型土壤动物群落结构的时空动态 笔管榕榕小蜂的群落结构与物种多样性 海洋生态资本理论框架下的生态系统服务评估 中国地貌区划系统一以自然保护区体系建设为目标..... 生态植被建设对黄土高原农林复合流域景观格局的影响 华北农牧交错带农田-草地景观镶嵌体土壤水分空间异质性 中国北方春小麦生育期变化的区域差异性与气候适应性 中国南方喀斯特石漠化演替过程中土壤理化性质的响应 气候变化对东北沼泽湿地潜在分布的影响…… 内蒙古不同类型草地土壤氮矿化及其温度敏感性 黑河中游荒漠绿洲区土地利用的土壤养分效应 成都平原北部水稻土重金属含量状况及其潜在生态风险评价 大西洋中部延绳钓黄鯺金枪鱼渔场时空分布与温跃层的关系

夏季台湾海峡南部海域上层水体的生物固氮作用 北长山岛森林乔木层碳储量及其影响因子

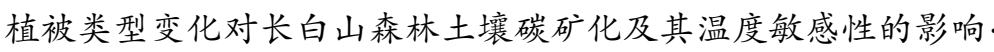
油松遗传结构与地理阻隔因素的相关性 ... 基于辅助环境变量的土壤有机碳空间插值 以黄土丘陵区小流域为例
肖以华, 李昫, 旷远文, 等 (6209) 汪振华, 赵 静, 王 凯, 等 (6218) 陈云龙, 单秀娟, 周志鹏, 等 (6227) . 李 娜, 张雪萍, 张利敏 (6236) 陈友铃, 陈晓倩, 吴文珊, 等 (6246) 陈 尚, 任大川, 夏 涛, 等 (6254) . 郭子良, 崔国发( 6264) 易扬, 信忠保, 覃云斌, 等 (6277) 王红梅, 王仲良, 王 壁, 等 (6287) 俄有浩, 霍治国, 马玉平, 等 (6295) ... 盛茂银, 刘洋, 熊康宁 (6303) 贺伟, 布仁仓, 刘宏娟, 等 (6314) 朱剑兴, 王秋风, 何念鹏, 等 (6320) 马志敏, 吕一河, 孙飞翔, 等 (6328) 秦鱼生, 喻华, 冯文强, 等 (6335) 杨胜龙, 马军杰, 张禹, 等 (6345) 林 峰, 陈 敏, 杨伟锋, 等 (6354) 石洪华, 王晓丽, 王 嫒, 等 (6363) 王丹, 吕瑜良, 徐 丽, 等 (6373) 孟翔翔, 狄晓艳, 王孟本, 等 (6382)

文 雯, 周宝同, 汪亚峰, 等 (6389)

基于生命周期视角的产业资源生态管理效益分析一以虚拟共生网络系统为例

施晓清,李笑诺,杨建新 (6398)

生态脆弱区贫困与生态环境的博弯分析 祁新华, 叶士琳, 程 暗, 等 (6411)

“世博”背景下上海经济与环境的耦合演化 倪 尧, 岳文泽, 张云堂, 等 $(6418)$

期刊基本参数: CN 11-2031/Q * $1981 * \mathrm{~m} * 16 * 464 * \mathrm{zh} * \mathrm{P} * ¥ 90.00 * 1510 * 55 * 2013-10$

封面图说: 毛乌素沙地南缘沙丘的生物结皮一一生物土壤结皮广泛分布于干旱和半干旱区, 它的形成和发育对荒漠生态系统 生态修复过程产生重要的影响。组成生物结皮的藻类、苔藓和地衣是常见的先锋植物, 它们不仅能在严重干旱缺 水、营养贫㾑恶劣的环境中生长、繁殖, 并且能通过其代谢方式影响并改变环境。其中一个重要的特点是, 生物结皮 表面的凝结水显著大于裸沙。研究表明, 凝结水是除降雨之外最重要的水分来源之一, 在水分极度匮乏的荒漠生态 系统, 它对荒漠生态系统结构、功能和过程的维持产生着重要的影响。

彩图及图说提供: 陈建伟教授 北京林业大学 E-mail: cites.chenjw@163.com 
罗巧玉，王晓娟，李媛媛，林双双，孙莉，王强，王茜，金樑.AM 真菌在植物病虫害生物防治中的作用机制.生态学报,2013,33(19):5997-6005. Luo Q Y, Wang X J, Li Y Y, Lin S S, Sun L, Wang Q, Wang Q, Jin L. Mechanism of biological control to plant diseases using arbuscular mycorrhizal fungi. Acta Ecologica Sinica, 2013,33(19):5997-6005.

\title{
AM 真菌在植物病虫害生物防治中的作用机制
}

\author{
罗巧玉，王晓娟，李媛媛，林双双，孙 莉，王 强，王 茜，金 樑* \\ (兰州大学 草地农业生态系统国家重点实验室 草地农业科技学院, 兰州 730020)
}

\begin{abstract}
摘要: 丛枝菌根 (Arbuscular Mycorrhizae,AM) 真菌是一类广泛分布于土壤生态系统中的有益微生物, 能与大约 $80 \%$ 的陆生高等 植物形成共生体。由土传病原物侵染引起的土传病害被植物病理学界认定为最难防治的病害之一。研究表明, AM 真菌能够 拮抗由真菌、线虫、细菌等病原体引起的土传性植物病害,诱导宿主植物增强对病虫害的耐/抗病性。当前, 利用 AM 真菌开展 病虫害的生物防治已经引起生态学家和植物病理学家的广泛关注。基于此,围绕 AM 真菌在植物病虫害生物防治中的最新研 究进展, 从 AM 真菌改变植物根系形态结构、调节次生代谢产物的合成、改善植物根际微环境、与病原微生物直接竞争人侵位点 和营养分配、诱导植株体内抗病防御体系的形成等角度,探究 AM 真菌在植物病虫害防治中的作用机理, 以期为利用 AM 真菌 开展植物病虫害的生物防治提供理论依据,并对本领域未来的发展方向和应用前景进行展望。
\end{abstract}

关键词:AM 真菌;宿主植物;病原体;抗病性;生物防治

\section{Mechanism of biological control to plant diseases using arbuscular mycorrhizal fungi}

LUO Qiaoyu, WANG Xiaojuan, LI Yuanyuan, LIN Shuangshuang, SUN Li, WANG Qiang, WANG Qian, JIN Liang*

State Key Laboratory of Grassland Agro-Ecosystem, School of Pastoral Agriculture Science and Technology, Lanzhou University, Lanzhou 730020, China

Abstract: Arbuscular mycorrhizal (AM) fungi are one of the widely spread micro-organisms, which could form symbionts with more than $80 \%$ of the vascular plants in natural ecosystems. It has been showed that AM symbionts could improve plant nutrients and water absorption; increase the resistance ability to stress conditions, thus AM fungi could enhance the host plant growth. The plant soil-borne diseases caused by soil-borne pathogens, including fungi, nematodes and bacteria, are considered as one of the most difficult controlling diseases in agriculture ecosystem. Previous studies have been demonstrated that AM symbionts could increase plant resistance to diseases, and to antagonize soil-borne pathogens. Thus, using AM fungi as a biological control method to antagonize soil-borne pathogens has received increasing interests by phytopathologists and ecologists. On the basis of this, the mechanisms of resistance to diseases induced by AM fungi were summarized in this paper. Mechanisms covered in this review include root morphology alteration, regulation of secondary metabolite production, improvement of rhizosphere environments, competition with pathogenic microorganisms on invasive sites and on nutrition distribution in host plants, and formation of defense systems in plants. Firstly, the characteristics of root morphology alterations were explained, including how AM fungi influence their structures and functions. Secondly, the regulation of AM fungi to secondary metabolites was illustrated. Several types of products, including phytoalexin, callose, alkaloid and phenols were reviewed. Thirdly, AM fungi could improve the rhizosphere environments by influence soil physical and chemical proprieties, and enhance the growth of other beneficial microorganism in rhizosphere soil. Fourth, AM fungi could compete with pathogenic microorganisms. The two kinds of microorganisms maybe compete for the same invasive sites in root

基金项目: 国家自然科学基金资助项目(No.31270558); 国家公益性行业(农业)科研专项经费资助 (201203041)；兰州大学中央高校基本科研 业务费专项资金资助 (lzujbky-2013-86)

收稿日期: 2013-05-30; 修订日期: 2013-07-23

*通讯作者 Corresponding author.E-mail: liangjin@ lzu.edu.cn 
systems, and thus they could regulate the nutrition distribution. Fifth, AM fungi could induced the host plant to form the defense systems in plants, including improvement the concentrations of phytohormone, induced the production of signal substrates, regulation of genes expression and enhanced the proteins production, thus AM fungi could enhance the resistance ability of host plant to pathogenic microorganisms. The aim of this paper was to enhance the potential use of AM fungi as a biological control method for preventing plant diseases in future.

Key Words : arbuscular mycorrhizal fungi; host plants; pathogens; resistance to disease; biological control

当前,随着化学农药的广泛使用,农田生态系统中真菌、细菌、线虫等病原体对农药的耐药性日益增强, 而其天敌则被大量 杀灭,致使病虫害日益猖獗。同时,化学农药具有污染大气、水体和土壤的特性,可以残留在动、植物体内,通过食物链进人人 体, 危害人类健康 ${ }^{[1]}$ 。随着人民生活水平的不断提高, 由农药、化肥引起的食品安全问题已经受到广泛关注。因此, 寻找防治 植物病虫害的绿色、环境友好型治理技术已经成为环境科学家和植物病理学家研究的热点之一。生物防治就是其中备受关注 的一项技术与方法。

生物防治 (Biological Control) 是指利用生物物种间的相互关系, 以一种或一类生物抑制、消灭另一种或另一类有害生物的 防治方法 ${ }^{[2-3]}$ 。因其具有高效低耗、对环境安全、功能多样等诸多优点而受到土壤学家、植物病理学家和生态学家的广泛关注, 目前采用寄生性和捕食性昆虫 (天敌)治理病虫害的研究已取得重大突破,相关技术已经推广应用。此外,采用微生物进行生 物防治也已取得显著进展 ${ }^{[3-4]}$ 。

丛枝菌根 (Arbuscular Mycorrhizae, AM) 是陆地生态系统中广泛分布的一类与植物根系共生的有益微生物。地球上 $80 \%$ 的 陆生高等植物均能与其建立共生关系, 形成特定的 “菌根” 结构 ${ }^{[5]}$ 。菌根共生体的形成能够改善宿主植物的营养状况, 促进宿 主植物提高对土壤中 $\mathrm{P} 、 \mathrm{~N} 、 \mathrm{~K} 、 \mathrm{Zn} 、 \mathrm{Mn} 、 \mathrm{Fe} 、 \mathrm{Cu} 、 \mathrm{Ca}$ 等矿质元素的吸收 ${ }^{[6]}$, 提高植物的生物量生产 ${ }^{[5]}$, 增强宿主植物对非生物胁迫, 如干旱 ${ }^{[7]}$ 、盐渍 ${ }^{[8]}$ 、重金属污染 ${ }^{[9]}$ 等的耐受能力。菌根际 (Mycorrhizosphere) 是由植物根系、线虫、细菌、AM 真菌和其他真菌通 过竞争、拮抗、协同效应等种间关系相互作用构成的集合体,对保持土壤生态系统的动态平衡发挥重要作用,其中微生物-微生 物之间的相互作用对植物生长影响显著 ${ }^{[5]}$ 。AM 真菌又是菌根际内最普遍、生物量最大、作用最显著的有益真菌类群, 对土传 病原体具有一定的拮抗或抑制效应 ${ }^{[10-12]}$ 。研究表明, AM 真菌能够通过改变植物根系形态或解剖结构, 调控宿主植物体内次生 代谢产物的形成, 改善根际环境的理化性状, 与病原物竞争光合产物和侵染空间,激活、诱导植株体内抗病防御体系的启动等多 种机制，降低真菌、线虫、细菌等病原体对黄瓜(Cucumis sativus)、草莓(Fragaria ananassa)、西红柿 (lycopersicon esculentum)、柑橘 (Citrus reticulata)、油橄榄( Olea europaea)、截形苜宿（Medicago truncatula）、香瓜 (Cucumis melo)、玉米 (Zea mays)、马铃薯 (Solanum tuberosum)、香蕉 (Musa nana) 等植物的危害程度,减少农药使用量 ${ }^{[13-16]}$ 。目前已经证实的可有效控制植物土传病害 的 AM 真菌超过 30 种 ${ }^{[17]}$, 因此研究 AM 真菌在植物病虫害生物防治中的作用机制具有重要的理论和应用价值。基于此,本文 就近年来国内外有关 AM 真菌在生物防治中增强宿主植物耐/抗病性的机制进行综述, 同时对利用 AM 真菌进行植物病虫害防 治的前景进行展望。

目前,利用 AM 真菌进行植物病虫害防治的研究日趋增多,分析其相关机理主要包括改变植物根系形态结构、调节次生代 谢产物的合成、改善植物根际微环境、直接与病原微生物竞争人侵位点和营养、诱导植株抗病防御体系的形成等(图 1 ), 现分述 如下:

\section{1 改变植物根系形态结构}

病原体侵染植物根系必须通过细胞壁进人细胞,而 AM 真菌共生能够使宿主植物根系增长、增粗, 分枝增加; 加速细胞壁木 质化, 使根尖表皮加厚、细胞层数增多; 改变根系形态结构, 从而有效减缓病原体侵染根系的进程 ${ }^{[18]}$ (图 $\left.1 \mathrm{~A}\right)$ 。在大丽轮枝孢 (Verticillium dahliae) 胁迫下, 与摩西球囊霉(Glomus mosseae) 和幼套球囊需( G. etunicatum) 共生的陆地棉 (Gossypium hirsutum) 根 系木质部结构增多,栅栏组织和导管变形, 导管处产生胶状物质, 细胞变形固缩, 颜色加深, 细胞壁明显加厚、木质化, 液泡数量 显著减少, 线粒体内褶消失, 根系产生的一系列结构性变化均有利于提高宿主植物对大丽花轮枝孢的抵抗能力 ${ }^{[19]}$ 。AM 真菌能 在宿主植物根系表皮和内皮层形成菌丝体网络、胼胝质及由非酯化果胶堆积的乳头状结构(图 1B), 对病原体穿透根系细胞组 织及进一步侵染起到阻碍作用 ${ }^{[20]}$, 根系解剖结构的变化改变病原物的侵染动力学。菌根化植株根系的变化还体现在诱导细胞 壁产生富含羟基脯氨酸糖蛋白 (Hydroxyproline-rich Glycoprotein, HRGP)。HRGP 是植物细胞壁上的糖-蛋白质线性复合分子,作 为细胞壁结构物质,可以提高宿主植物细胞壁的强度,使细胞壁不能被病原物侵染过程中分泌的蛋白酶、纤维素酶、半纤维素酶 等分解。另一方面, 病原体人侵植物过程中 HRGP 起凝集素作用, 把病原体固定在细胞壁上(图 1C), 从而阻止病原体侵人植物 细胞 ${ }^{[21]}$ 。

AM 真菌除了影响宿主植物根系结构外,其细胞壁上存在的一些物质也能起到抑制病原菌的作用(图 1C)。研究表明,一 
些球囊雼属 (Glomus) 的 AM 真菌根外菌丝、芽管的内壁及狍子细胞壁上存在 $\beta-1,3$-葡聚糖, 而盾巨狍囊震属 (Scutellospora) 或巨 孢囊需属 (Gigaspora) 真菌中不存在 $\beta-1,3$-葡聚糖 ${ }^{[22]}$ 。 $\beta-1,3$-葡聚糖是细胞壁的结构成分, 其在 AM 真菌体内的存在说明 AM 真菌对病原微生物具有一定的屏障作用。可见, AM 真菌能够通过改变植物根系的解剖结构及自生的结构物质来增强宿主植 物对病虫害的抵御性,达到生物防治的作用。

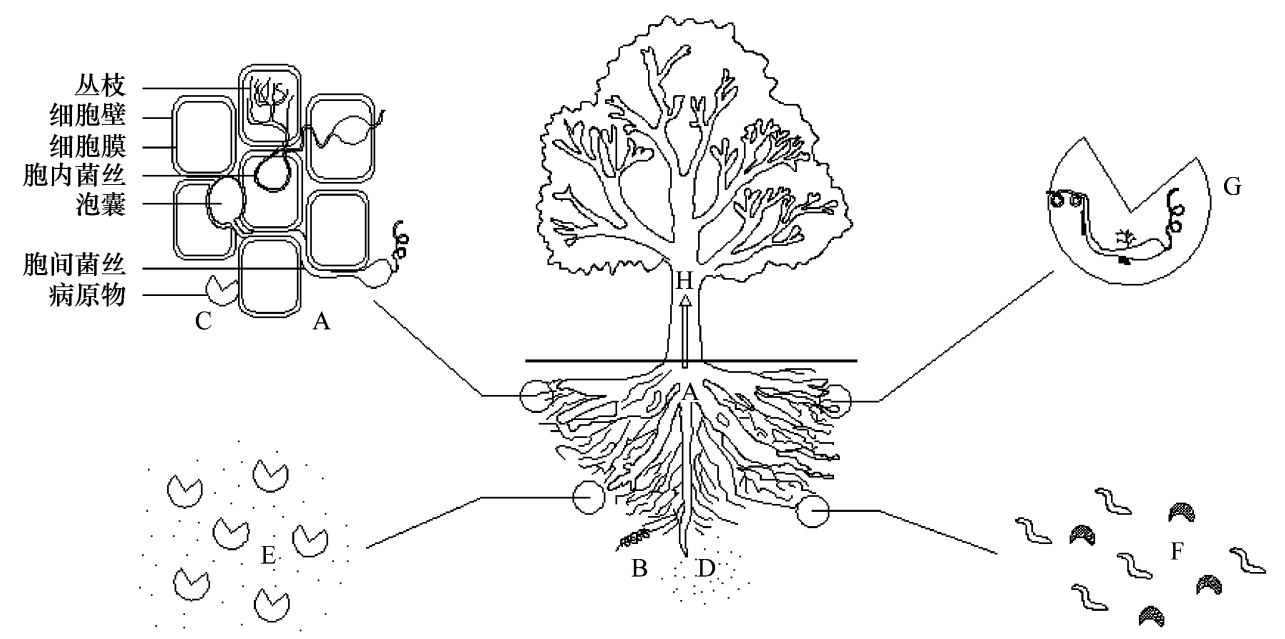

图 1 AM 真菌-植物共生体对病虫害进行生物防治的作用机制示意图

Fig.1 Schematic diagram of biological control mechanisms in arbuscular mycorrhizal (AM) fungi symbiosis with plants

A : 根系分枝增多, 根尖表皮加厚, 细胞壁木质化; B: AM 真菌菌丝体网络在根系表皮起屏障作用; C: Hydroxyproline-rich Glycoprotein ( HRGP) , $\beta-1,3$-葡聚糖等物质将病原物凝集于细胞壁; D : 改善土壤结构; $\mathrm{E}$ : 根系分泌物杀死病原物; F: AM 真菌刺激有益微生物生长繁 殖; G: AM 真菌寄生在病原物体内; $\mathrm{H}$ : 改善植株对养分、水分的吸收状况, 同时与病原物竞争营养物质

\section{2 调节次生代谢产物的合成}

菌根共生体能够调节宿主植物生理代谢过程中次生代谢产物的种类和数量,这是 AM 真菌诱导植株抗病性的一个重要机 制 ${ }^{[23-24]}$ 。AM 真菌根内菌丝和根外菌丝表面均能产生植保素、胼胝质、生物碱、酚类等化学物质,这些次生代谢产物有利于植株 抵御病害所造成的逆境条件 ${ }^{[25]}$ 。

植保素是植物受病原微生物侵染过程中产生的一类抗性化合物, 其产生速度和累积量与植物的抗病性有关。一般植保素 在受侵染细胞周围积累,起屏障隔离作用,防止病原体进一步扩散。摩西球囊需可以诱导植物根系产生植保素应激反应,提高 植物抗病性 ${ }^{[26]}$ 。接种根内球囊需 (G. intraradices) 促进根系中胼胝质沉积, 保护黄瓜免受瓜炭疽菌 ( Colletotrichum orbiculare) 毒 害 ${ }^{[27]}$ 。长春花 (Catharanthus roseus) 受 AM 真菌侵染后其叶片中长春花碱含量显著增加, 提高了植株对生物胁迫的抗逆性 ${ }^{[28]}$ 。 酚类物质家族包含黄酮类、酚羧酸等多种化合物,这些物质均与植物的信号分子及防御系统联系在一起 ${ }^{[29]}$, 而黄酮类物质还能 增加 AM 真菌的侵人位点并提高其侵染率 ${ }^{[30]}$ 。研究发现, 菌根化植物根系酚类物质含量发生变化, 与 AM 真菌共生的陆地棉 内积累了大量酚类化合物, 这些化合物可以提高宿主植物抵御大丽轮枝孢的能力 ${ }^{[31]}$ 。接种摩西球囊霉的草䒯地上部分和根系 中草莓枯萎病 (Fusarium oxysporum f. sp. fragariae)、胶狍炭疽菌 (C. gloeosporioides)病害发生率及病症严重程度均显著降低,植 株总多酚含量、抗坏血酸含量增加 ${ }^{[32]}$ 。Zhu 等通过分根试验发现, 地表球囊需 (G. versiforme) 能够诱导西红柿植株产生对茄青 枯病菌 (Ralstonia solanacearum) 的系统抗性 ${ }^{[32]}$, 其根系中酚类物质含量显著增加, 酚类物质的增加同时发生在茄青枯病菌侵染 根段和未侵染根段 ${ }^{[33]}$, 因此植物系统抗性与酚类物质含量的增加密切相关。但也有研究发现, 接种 AM 真菌与未接种 AM 真 菌的椰菄树 (Phoenix dactylifera) 受椰冭失绿病菌 (F. oxysporum f. sp. albedinis) 感染后酚类化合物没有显著变化,但菌根化植株 体内积累了大量的内羟基肉桂酸的衍生物,从而提高了其抵御椰㫫失绿病菌的能力 ${ }^{[34]}$ 。

\section{3 改善植物根际微环境}

$\mathrm{AM}$ 真菌与植物形成共生关系后, 真菌菌丝的发育能够改变宿主植物根细胞膜的通透性、改变根系分泌物的组分和数量, 影响根际土壤物理、化学性状,进一步导致根围微生物的种群结构和数量发生变化( 图 1D一F)。研究表明, 菌根及其根外菌丝 可贯穿于土壤颗粒间极小的孔隙,其分泌物如球囊䨘素相关蛋白 (GRSP)、有机酸、多胺等可作为土壤颗粒间粘着的吸附剂,促 进土壤团粒结构形成, 改善土壤的 $\mathrm{pH}$ 、水稳定性、通气性、透水性,进一步提高氧化还原电位 (Eh), 促进植株正常生长以抵御病 害侵人 ${ }^{[35]}$ 。与 AM 真菌共生的植物根系产生的分泌物可直接影响其它土壤真菌 ${ }^{[26,36-37]}$ 、线虫 ${ }^{[38]}$ 和细菌 ${ }^{\left[{ }^{[39}\right]}$ 的生长发育与繁 殖, 使土壤中微生物群落在结构、性质、数量及空间分布上发生变异。菌根化西红柿根系渗出液可以持续的麻痹线虫, 从而减少 线虫对根系的侵人 ${ }^{[38]}$, 也会排斥烟草疫霉菌 (Phytophthora nicotianae) 的游动孢子, 使其不能接近植物根系 ${ }^{[40]}$ 。此外, AM 真菌 
还可以与土壤有益微生物相互促进, 产生协同效应, 尤其是可以刺激对土传病原菌具有拮抗作用的微生物活性, 使根围中对植

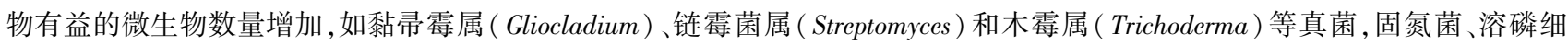
菌、苂光假单胞菌 (Pseudomonas fluorescence)、芽狍杆菌等促进植物生长的细菌 (Plant Growth Promoting Rhinoacteria, PGPR) 以及 放线菌等 ${ }^{[39,41]}$, 这些有益微生物也会减少病原体的数量、降低病原微生物对植株的侵染机会, 从而间接提高植物对病原体的抵 御能力。PGPR 还能强化 AM 真菌与植物的共生关系 ${ }^{[42]}$ 。因此, 改变植物根际土壤理化性质及菌根际微生物区系是 AM 真菌 重要的抗病机制之一。

\section{4 与病原微生物的竞争效应}

4.1 竞争人侵位点

AM 真菌作为一种土壤根际活体营养 (Biotrophic) 共生微生物, 常常与土传病原体具有相同的生态位和人侵位点, 因此在自 然生境条件下, AM 真菌与病原体必然存在空间竞争关系,其生防作用主要是减少根系表皮病原体的初侵染和再侵染。AM 真 菌侵染植物根系后, 寄生类病原体的人侵位点数目明显减少 ${ }^{[42]}$ 。研究发现, 菌根化植株中受 AM 真菌侵染的根段及邻近未被 侵染根段均没有或很少有大豆胞囊线虫 (Heterodera glycines) ${ }^{[44]}$ 。补娟等以不同的顺序对陆地棉接种 AM 真菌和病原菌,证实 AM 真菌与病原菌之间存在对侵染位点的竞争 ${ }^{[31]}$ 。当先接种聚生球囊霉 ( G. fasciculatum) 时, 根系位点被 AM 真菌侵染, 则可 显著抑制瓜果腐需菌(Pythium aphanidermatum) 在沉香(Aquilaria agallocha) 根系组织中的发展,降低植株的发病指数和猝倒症 状 ${ }^{[45]}$ 。菌根化植株中未被 AM 真菌菌丝侵染的根段也具有抵御病原体的系统抗性,且增加了植物地上部分对某些病害的抵抗 能力 ${ }^{[24]}$, 是 AM 真菌提高宿主植物系统抗性的重要组成部分。同时,线虫的虫掼中往往可以看到 AM 真菌的泡囊、菌丝甚至丛

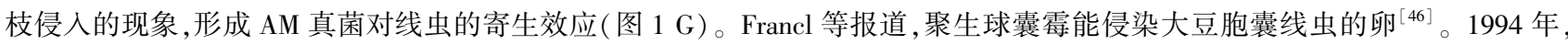
刘杏忠等研究发现大豆孢囊线虫的狍囊内有 AM 真菌的厚垣狍子定殖 ${ }^{[47]}$, 也表明 AM 真菌对病原体具有一定的寄生作用,但 有关 AM 真菌对病原微生物的寄生关系及其生防效应尚待深人研究。

4.2 竞争营养分配

1993 年, Eissenstatet 等采用 ${ }^{14} \mathrm{C}$ 标记技术检测菌根化柑橘根系, 发现释放到根围中的 ${ }^{14} \mathrm{C}$ 很少 ${ }^{[48]}$, 因此根围微生物之间必然 存在对光合产物的竞争效应。AM 真菌和病原物相互竞争来自宿主植物根系的光合产物,当光合产物首先被 AM 真菌利用时, 病原物获取的机会就会减少, 从而限制病原物的生长和繁殖。另外, AM 真菌能够改善宿主植物对矿质营养和水分的吸收(图 1 $\mathrm{H})$ 。研究发现, 广泛分布于土壤中的 AM 真菌根外菌丝体相互交错形成庞大的菌丝网,从而扩大了根系对水分、营养物质,尤 其是磷酸盐和硝酸盐的吸收范围,同时对不同植物间的水分和养分进行再分配,使植物在一定程度上获得了另一条有效的水 分、养分传输途径 ${ }^{[49]}$ 。菌根通过增强植株对营养物质和水分的吸收, 补偿了因病原菌侵染造成的根系生物量和功能的损失, 从 而间接减轻病原微生物引起的危害, 提高宿主植物的耐病能力 ${ }^{[50]}$ 。对尖镰狍 $(F$. oxysporum) 胁迫条件下的西红柿接种 AM 真 菌能够促进植株对 $K 、 N 、 P 、 C a 、 M n 、 Z n$ 等元素的吸收, 提高叶绿素及可溶性糖含量, 促进植株分支、叶片数增多, 生物活力增强, 间接提高植株对病虫害的而受性 ${ }^{[51]}$ 。研究发现, 受南方根结线虫 (Meloidogyne incognita) 和爪哇根结线虫 (M. javanica) 危害的 油橄榄, 接种 $\mathrm{AM}$ 真菌后其生长状况显著改善, 生物量增加 $88.9 \%{ }^{[52]}$ 。

\section{5 诱导植株抗病防御体系的形成}

5.1 促进植物激素合成

植物激素作为植株内的痕量信号分子, 在调节植物的生长发育和对环境的应答过程起十分重要的作用。在 AM 真菌生长 及与宿主植物建立共生关系过程中 AM 真菌能够直接合成或者诱导植物体内产生一些激素类物质, 如生长素 ( Auxin, IAA)、细 胞分裂素 (Cytokinin, CK) 、赤霉素 (Giberellin Acid,GA)、油菜素内酯 (Brassinosteroids, BR)、莱莉酸( Jasmonic Acid, JA)、水杨酸 (Salicylic Acid, SA)、乙烯 (Ethylene,ET)、脱落酸 (Abscisic Acid,ABA) 等,这些激素也参与了 AM 真菌诱导宿主植物产生病虫害 防御体系的建立 ${ }^{[53]}$ 。

研究发现,接种地表球囊霉的黄瓜植株具有较高含量 IAA、GA、玉米素(Zeatin), 生长促进物质含量的相对增加与增强植株 对茄丝核菌的抗病能力有关,其中 IAA 在植株对病菌侵染的防御过程中具有一定的作用 ${ }^{[54]}$ 。Ortu 等发现受 AM 真菌侵染后截 形苜宿体内 GA 合成基因上调 ${ }^{[55]}$ 。菌根化植株茎叶内 IAA、GA、ET、CK 和 ABA 等内源激素的含量均高于未接种植株, AM 真菌 通过影响植物内源激素含量和它们之间的平衡, 促进植物生长, 间接增强抗病性; 植物激素可能是逆境基因表达的启动因子, 它 能诱导许多新基因表达及蛋白质合成 ${ }^{[56]}$ 。

5.2 诱导植物信号物质合成

$A M$ 真菌与植物共生后能诱导合成一氧化氮 $(\mathrm{NO}) 、 J A 、 S A 、 E T 、$ 过氧化氢 $\left(\mathrm{H}_{2} \mathrm{O}_{2}\right) 、 A B A 、 \mathrm{Ca}^{2+}$ 信号、糖信号等多种信号物质，

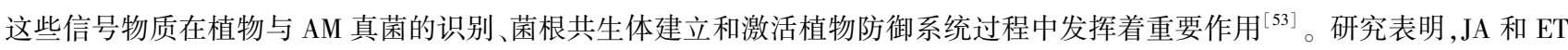
通常抵御腐生型病原物, 而 SA 对活体营养病原物具有一定的抑制作用。当植物被病原体侵染时, JA 和 ET 与植物系统诱导性 抗性( ISR) 有关, SA 与植物系统获得性抗性 (SAR) 有关 ${ }^{[57]}$ 。

近年来, NO 已经成为植物细胞信号传导研究领域的热点之一。作为信号分子, NO 参与一系列与植物防御系统相关的信 
号传导和基因表达过程 ${ }^{[58-59]}$ 。NO 在植物体内的积累与 AM 真菌的共生密切相关,接种珍珠巨孢囊䨖 ( Gi. margarita) 的截形苜 宿叶片和根系中 NO 含量分别是对照处理的 3.3 和 1.9 倍, 说明 AM 真菌对与系统抗性相关的 NO 的积累起诱导作用 ${ }^{[58]}$ 。菌根 诱导产生的 JA 能够激活植物体内的防御系统, 从而提高植物对病原体的抗性 ${ }^{[53]}$ 。西红柿幼苗根系感染尖镰孢 $20 \mathrm{~d}$ 后分别接 种聚生球囊霉和大果球囊需 (G. macrocarpum) , 发现菌根化的西红柿茎叶中 JA 含量是非菌根化植株的 9 倍, 病害程度分别降低 $78 \%$ 和 75\% ${ }^{[60]}$ 。目前, SA 已经被公认为 AM 真菌诱导植物产生系统抗病性的主要信号物质 ${ }^{[61]}$ 。El-Khallal 等研究发现, 接种 摩西球囊霉同时外施 SA 能有效抑制尖镰狍对西红柿的感染, 降低病情指数和枯萎程度 ${ }^{[51]}$ 。根内球囊霉能提高香瓜因受尖镰 孢侵染而降低的植物激素含量,诱导 JA 和 SA 信号途径,使香瓜对尖镰狍的防御系统增强 ${ }^{[36]}$ 。但也有研究发现接种根内球囊 霉的烟草(Nicotiana attenuata) 植株内源 JA 和 SA 含量没有发生显著性变化, ET 释放量甚至轻微降低 ${ }^{[62]}$ 。可见, 不同 AM 真菌 种类对不同宿主植物信号物质的诱导存在差异,相关机制尚待深人研究。

5.3 调控基因表达

AM 真菌能通过诱导与植物防御反应相关基因的表达,如 PAL5 基因和几丁质酶基因 $C h i b 1^{[63]}$,或通过调控各种抗病基因 的表达量及特异性表达来增强宿主植物的抗病性 ${ }^{[64]}$ 。

研究表明,对感染了大豆胞囊线虫的大豆 (Glycine max) 接种 AM 真菌,利用 Northern 杂交及逆转录 Polymerase Chain Reaction (PCR) 技术分析测定根系中与几丁质酶和苯丙氨酸解氨酶(Phenylalanine Ammonialyase, PAL) 相关的基因 Chib1、PAL5 的 mRNA 表达,发现 AM 真菌能够在转录水平上调控这些与抵御线虫相关的抗病基因,使其表达量和表达强度增强 ${ }^{[63]}$ 。2002 年 Tahiri-Alaoui 等从与摩西球囊需共生的西红柿根系中分离提取到基因 Le-MI-13, 该基因编码一种与介导蛋白质降解、开放或 关闭基因转录的泛素相似的氢基酸序列;利用 Northern 杂交技术表明此基因的转录只存在于菌根化西红柿根系中,而未接种西 红柿根系中未发现, 表明 AM 真菌是该基因特异性转录及提高植株抗病性的诱导因子 ${ }^{[65]}$ 。通过 16000 式单核苷酸阵列和实时 定量 PCR 研究发现, AM 真菌诱导截形苜宿植株体内与防御性相关的基因转录产物发生剧烈变化, 导致植株体内产生局部和系 统性防御反应, 抵御油菜黄单胞菌 (Xanthomonas campestris) 对植株的侵害 ${ }^{[64]}$ 。对预先接种摩西球囊需的两个感病玉米品种 (Yuenong-9、Gaoyou-115) 接种茄丝核菌 (Rhizoctonia solani), 发现菌根化植株体内产生的防御反应更加迅速和强烈, 两种玉米叶 片内与抗病性相关的 $A O S 、 P R 2 \mathrm{a}$ 和 $P A L$ 基因, 及丁布 (2, 4-dihydroxy-7-methoxy-2 H-1, 4- benzoxazin-3(4 H) -one, DIMBOA) 合成 途径中的关键基因 $B X 9$ 均被强烈诱导表达 ${ }^{[26]}$ 。非菌根化的两种不同基因型西红柿 (野生型 76R 和突变型 $r m c$ ) 感染茄丝核菌 后体内相关防御基因的表达量相同, 当接种菌根后突变型 $r m c$ 植株胞外 PR-1,胞内 $G l u B A S$ 和 Chi9 的 mRNA 表达更加强烈 ${ }^{[37] 。}$ 通过实时定量 PCR 分析发现, 菌根化马铃薯叶片的疫需菌 (P. infestans) 发病指数和病害症状之所以减轻, 可能和菌根化马铃薯 中与植株系统抗性相关的 $P R \mathrm{l}$ 和 $P R 2$ 基因的诱导表达有关 ${ }^{[66]}$ 。AM 真菌与植物建立互惠共生关系的过程中产生参与 JA 合成 的关键酶, 能有效催化 JA 合成, 菌根化截型苜宿根系中 JA 的主要合成酶丙二烯氧化物环化酶 (Allene Oxide Cyclase, AOC) 的 cDNAs 表达增强,积累的内源 JA 含量上升 ${ }^{[67]}$ 。

5.4 提高防御酶活性、诱导病程相关蛋白的合成

AM 真菌与宿主植物形成共生体的过程中, 能够激活很多防御性酶类, 如参与酚类物质代谢的多酚氧化酶 (Polyphenol Oxidase,PPO)、过氧化物酶 (Peroxidase, POD); 参与植保素、木质素、黄酮/异黄酮生物合成的查尔酮酶异构酶 (Chalcone Isomerase, CHI); 参与类黄酮合成的查尔酮合成酶 (Chalcone Synthase, CHS); 参与苯丙烷类物质代谢的苯丙氨酸解氨酶 (PAL), 同时一些与抗病相关的防御性蛋白 (如 Pathogenesis Related Protein,PR 蛋白) 也开始特异性表达 ${ }^{[68-69] 。}$

PAL 的活性可以作为植物抗病性的一个生理指标, 对感染尖镰狍的西红柿幼苗接种 AM 真菌, 茎叶中 PAL 的活性明显增 强, 可以显著减缓病害症状 ${ }^{[60]}$ 。接种摩西球囊霉的草莓植株中超氧化物歧化酶( Superoxide Dismutase, SOD) 活性和 1, 1-二苯基 苦基苯肼 (1, 1-Diphenyl-2-picrylhydrazyl,DPPH) 自由基清除活性增强,植株抗氧化能力显著提高, 进而增强了对胶孢炭疽菌和 尖镰狍的抗性,其中对尖镰狍的抵抗水平更高 ${ }^{[32]}$ 。被摩西球囊需侵染的西红柿根系中葡聚糖酶、几丁质酶、PR 蛋白等与过敏 性坏死反应有关的物质含量均高于非菌根化植株 ${ }^{[70]}$ 。接种单狍球囊需 ( G. monosporum)、沙漠球囊霉 $(G$. deserticola)、明球囊霉 (G. clarum) 等菌剂后椰束树体内多酚氧化酶活性均显著增强, 可抑制楖柊失绿病菌病害的发生 ${ }^{[25]}$ 。最新研究发现, 根内球囊 霉能够分泌一种可与细胞核中病程相关蛋白转录因子 ERF19 产生相互作用的防御蛋白 $\mathrm{sp} 7, \mathrm{sp} 7$ 的表达能够减轻稻瘟病 (Magnaporthe oryzae) 引起的根系腐烂症状 ${ }^{[71]}$ 。

AM 真菌提高宿主植物耐/抗病性的机制是多方面的,可能是某种机制单独作用的结果,也可能受到多种机制的协同作用; AM 真菌诱导的抗病性类型可能是系统的,也可能是局部的 ${ }^{[24,50]}$ 。AM 真菌对病原体潜在的拮抗作用有效性取决于 AM 真菌、 宿主植物和病原体之间的相互关系, 同时受接种量、接种时期及土壤因子(肥力、 $\mathrm{pH}$ 、温度、湿度等)等非生物因素的影响。在农 田生态系统中,相关农业管理措施如耕作制度、施肥管理及病虫害管理等也会影响 AM 真菌生防作用的发挥 ${ }^{[44]}$, 只有各种因素 协调一致时,才能真正发挥 AM 真菌的生物防治作用。

\section{6 展望}

综上所述, AM 真菌通过多种直接或间接作用, 提高了宿主植物对病虫害的耐/抗性, 促进植物生长。对易感病植株或病害 
高发区接种适宜的 AM 真菌可有效控制病虫害的危害程度,起到生物防治作用。生物防治技术代表了植物病理学未来的发展 方向之一, 具有广阔的前景。然而,利用 AM 真菌进行生物防治是一项新兴的病虫害防治技术,很多基本理论和实践应用中出 现的问题亟待解决。因此, 尚需加强对以下领域的研究:

(1) 选育、驯化、构建抗/而病性较强的 AM 真菌菌株。目前国内外已经笁选出多种抗病 AM 真菌,但大多为直接使用菌株 或菌剂来防治病害, 因此其活性有效期及效果稳定性难以保证。未来应系统普查各地 AM 真菌的种质资源, 以常规和非常规方 法分离、篮选出适合不同宿主植物的耐/抗病性 AM 真菌菌株,建立 AM 真菌基因库。提取、纯化耐/抗病性 AM 真菌菌株内抗 菌物质(如抗菌蛋白、抗生素等)。研究拮抗菌的遗传背景, 克隆、分离能够表达抗菌物质的基因, 通过遗传工程技术, 构建高 效、多抗转基因工程菌。

(2) 进行 AM 真菌与其他有益微生物的组合研究。研究表明, AM 真菌和 PGPR 的双接种比单接种更能有效控制病害 ${ }^{[42]}$ 。 因此开展 AM 真菌对其它土壤微生物活性及群落结构影响的研究, 探究 AM 真菌与其他有益微生物的协同效应, 对强化 AM 真 菌与宿主植物的生物防治效果具有重要意义。

(3) 建立不同生态环境条件下 AM 真菌生物防治有效性的评价体系。AM 真菌的生防效果受众多生物因子和非生物因子 的影响 ${ }^{[4]}$, 因此应深人研究能够使植物受益最大化的调控因素, 如最佳接种时期、接种剂量、生态条件、耕作方式、施肥量等, 建 立一个科学的、有效的 AM 真菌生防效果评价标准,为利用 AM 真菌开展生物防治工作提供理论依据。

(4) 深人探究 AM 真菌对植株地上部分的生物防治作用。植物除受地下部的生物胁迫外, 还面临着地上部分的生物胁迫。 已有研究显示接种 AM 真菌能够防御地上有害昆虫和病原微生物 ${ }^{[24]}$, 但系统性的研究尚待加强。因此, AM 真菌对植株地上部 的防御作用及地上部分-病原体-AM 真菌之间的三重营养关系尚需进一步研究。

(5) 进一步深人研究 AM 真菌的抗病机制。未来研究中应利用同位素标记、分子生物学、激光共聚焦扫描显微等技术和基 因工程手段深人研究 AM 真菌对各种信号途径的影响及各信号物质之间的相关性, 探究 AM 真菌最先诱导哪个信号物质, 哪些 物质又是第二、第三被依次诱导产生? 基因的改变受哪个/些信号物质诱导产生? 定位、篮选出 AM 真菌诱导表达的相关抗性 基因,探究其产物的结构、功能及诱导表达机制。

\section{References:}

[ 1 ] Huang N X, Enkegaard A, Osborne L S, Ramakers P M J, Messelink G J, Pijnakker J, Murphy G. The banker plant method in biological control. Critical Reviews in Plant Sciences, 2011, 30(3): 259-278.

[ 2 ] van Driesche R G, Carruthers R I, Center T, Hoddle M S, Hough-Goldstein J, Morin L, Smith L, Wagner D L, Blossey B, Brancatini V, Casagrande R, Causton C E, Coetzee J A, Cuda J, Ding J, Fowler S V, Frank J H, Fueste R, Goolsby J, Grodowitz M, Heard T A, Hilll M P, Hoffmann J H, Hubert J, Julien M, Kairo M T K, Kenis M, Mason P, Medal J, Messing R, Miller R, Moore A, Neuenschwander P, Newman R, Norambuena H, Palmer W A, Pemberton R, Panduro A P, Pratt P D, Rayamajhi M, Salom S, Sands D, Schooler S, Schwarzländer M, Sheppard A, Shaw R, Tipping P W, van Klinkeni R D. Classical biological control for the protection of natural ecosystems. Biological Control, 2010, 54 (S1) : 2-33.

[ 3 ] Obrycki J J, Harwood J D, Kring T J, O'Neil R J. Aphidophagy by coccinellidae: application of biological control in agroecosystems. Biological Control, 2009, 51(2): 244-254.

[ 4 ] Gabriele B. Plant-microbe interactions promoting plant growth and health: perspectives for controlled use of microorganisms in agriculture. Applied Microbiology and Biotechnology, 2009, 84(1): 11-18.

[ 5 ] Smith S E, Read D J. Mycorrhizal Symbiosis. 3rd ed. New York: Academic Press, 2008.

[ 6 ] Grunwald U, Guo W B, Fischer K, Isayenkov S, Ludwig-Müller J, Hause B, Yan X L, Küster H, Franken P. Overlapping expression patterns and differential transcript levels of phosphate transporter genes in arbuscular mycorrhizal, Pi-fertilised and phytohormone-treated Medicago truncatula roots. Planta, 2009, 229(5): 1023-1034.

[ 7 ] Gianinazzi S, Gollotte A, Binet M N, van Tuinen D, Redecker D, Wipf D. Agroecology: the key role of arbuscular mycorrhizas in ecosystem services. Mycorrhiza, 2010, 20(8): 519-530.

[ 8 ] Lu X P, Du Q, Yan Y L, Ma K, Wang Z J, Jiang Q. Effects of soil rhizosphere microbial community and soil factors on arbuscular mycorrhizal fungi in different salinized soils. Acta Ecologica Sinica, 2012, 32(13) : 4071-4078.

[ 9 ] Hildebrandt U, Regvar M, Bothe H. Arbuscular mycorrhiza and heavy metal tolerance. Phytochemistry, 2007, 68(1): 139-146.

[10] Jung S C, Martinez-Medina A, Lopez-Raez J A, Pozo M J. Mycorrhiza-induced resistance and priming of plant defenses. Journal of Chemical Ecology, 2012, 38(6): 651-664.

[11] Miransari M. Interactions between arbuscular mycorrhizal fungi and soil bacteria. Applied Microbiology and Biotechnology, 2011, 89(4) : 917-930.

[12] Huang J H, Luo S M, Zeng S S. Mechanisms of plant disease resistance induced by arbuscular mycorrhizal fungi. Chinese Journal of Applied Ecology, 2003, 14(5): 819-822.

[13] Garg N, Chandel S. Arbuscular mycorrhizal networks: process and functions. A review. Agronomy for Sustainable Development, 2010, 30(3) : 
581-599.

[14] Artursson V, Finlay R D, Jansson J K. Interactions between arbuscular mycorrhizal fungi and bacteria and their potential for stimulating plant growth. Environmental Microbiology, 2006, 8(1): 1-10.

[15] Wang C X, Li X L, Qin L, Wang G Q, Zhou J C, Yang H M. Review on increasing resistance to pathogens by arbuscular mycorrhizal fungi. Chinese Journal of Biological Control, 2007, 23(s1) : 64-69.

[16] Li H Y, Liu R J, Su H R. Mechanism of increaseing plant disease resistance by AM fungi. Mycosystema, 2001, 20(3) : 435-439.

[17] Liu R J, Chen Y L. Mycorrhizology. Beijing: Science Press, 2007.

[18] Toljander J F. Interactions between Soil Bacteria and Arbuscular Mycorrhizal Fungi [ D ]. Uppsala: Swedish University of Agricultural Sciences, 2006.

[19] Cui W D, Long X Q, Hou X Q, Yang R, Bu J, Luo M. Effect of Verticillium wilt pathogen stress on the defensive enzymes and ultramicrostructure in the cotton root inoculated with AMF. Xinjiang Agricultural Sciences, 2009, 46(6) : 1235-1244.

[20] Pozo M J, Cordier C, Dumas-Gaudot E, Gianinazzi S, Barea J M, Azcon-aguilar C. Localized versus systemic effect of arbuscular mycorrhizal fungi on defence responses to Phytophthora infection in tomato plants. Journal of Experimental Botany, 2002, 53(368) : 525-534.

[21] Pamiske M. Molecular genetics of the arbuscular mycorrhizal symbiosis. Current Opinion in Plant Biology, 2004, 7(4) : 414-421.

[22] Pozo M J, Azcón-Aguilar C, Dumas-Gaudot E, Barea J M. $\beta$-1, 3-glucanase activities in tomato roots inoculated with arbuscular mycorrhizal fungi and/or Phytophthora parasitica and their possible involvement in bioprotection. Plant Science, 1999, 141(2): 149-157.

[23] Zubek S, Stojakowska A, Anielska T, Turnau K. Arbuscular mycorrhizal fungi alter thymol derivative contents of Inula ensifolia L. Mycorrhiza, 2010, 20(7): 497-504.

[24] Pozo M J, Azcón-Aguilar C. Unravelling mycorrhiza-induced resitance. Current Opinion in Plant Biology, 2007, 10(4) : 393-398.

[25] Jaiti F, Meddich A, El-Hadrami I. Effectiveness of arbuscular mycorrhizal fungi in the protection of date palm (Phoenix dactylifera L.) against bayoud disease. Physiological and Molecular Plant Pathology, 2007, 71(4/6) : 166-173.

[26] Song Y Y, Cao M, Xie L J, Liang X T, Zeng R S, Su Y J, Huang J H, Wang R L, Luo S M. Induction of DIMBOA accumulation and systemic defense responses as mechanism of enhanced resistance of mycorrhizal corn (Zea mays L.) to sheath blight. Mycorrhiza, 2011, 21(8) : $721-731$.

[27] Lee C S, Lee Y J, Jeun Y C. Observations of infection structures on the leaves of cucumber plants pre-treated with arbuscular mycorrhiza Glomus intraradices after challenge inoculation with Colletotrichum orbiculare. The Plant Pathology, 2005, 21(3) : 237-243.

[28] de la Rosa-Mera C J, Ferrera-Cerrato R, Alarcón A, Sánchez-Colín M D, Muñoz-Muñiz O D. Arbuscular mycorrhizal fungi and potassium bicarbonate enhance the foliar content of the vinblastine alkaloid in Catharanthus roseus. Plant and Soil, 2011, 349(1/2) : 367-376.

[29] Shaw L J, Morris P, Hooker J E. Perception and modification of plant flavonoid signals by rhizosphere microorganisms. Environmental Microbiology, 2006, 8(11): 1867-1880.

[30 ] Scervino J M, Ponce M A, Erra-Bassells R, Bompadre J, Vierheilig H, Ocampo J A, Godeas A. The effect of flavones and flavonols on colonization of tomato plants by arbuscular mycorrhizal fungi of the genera Gigaspora and Glomus. Canadian Journal of Microbiology, 2007, 53(6) : 702-709.

[31 ] Bu J, Cui W D, Luo M, Long X Q, Yang R. The effect of inoculation with AMF inoculum on growth and Verticillium wilt of cotton. Xinjiang Agricultural Sciences, 2009, 46(3): 549-555.

[32] Li Y H, Yanagi A, Miyawaki Y, Okada T, Matsubara Y. Disease tolerance and changes in antioxidative abilities in mycorrhizal strawberry plants. Journal of the Japanese Society for Horticultural Science, 2010, 79(2): 174-178.

[33] Zhu H H, Yao Q. Localized and systemic increase of phenols in tomato roots induced by Glomus versiforme inhibits Ralstonia solanacearum. Journal of Phytopathology, 2004, 152(10): 537-542.

[34] Jaiti F, Kassami M, Meddich A, Hadrami I E. Effect of arbuscular mycorrhization on the accumulation of hydroxycinnamic acid derivatives in data palm seedlings challenged with Fusarium oxysporum f. sp. Albedinis. Journal of Phytopathology, 2008, 156(11/12) : 641-646.

[35] Bais H P, Weir T L, Perry L G, Gilroy S, Vivanco J M. The role of root exudates in rhizosphere interactions with plants and other organisms. Annual Review of Plant Biology, 2006, 57(1) : 233-266.

[36] Martínez-Medina A, Pascual J A, Pérez-Alfocea F, Albacete A, Roldán A. Trichoderma harzianum and Glomus intraradices modify the hormone disruption induced by Fusarium oxysporum infection in melon plants. Phytopathology, 2010, 100(7) : 682-688.

[37] Gao L L, Smith A F, Smith S E. The rmc locus does not affect plant interactions or defence- related gene expression when tomato (Solanum lycopersicum) is infected with the root fungal parasite, Rhizoctonia. Functional Plant Biology, 2006, 33(3) : 289-296.

[38] Vos C, Claerhout S, Mkandawire R, Panis B, de Waele D, Elsen A. Arbuscular mycorrhizal fungi reduce root-knot nematode penetration through altered root exudation of their host. Plant and Soil, 2011, 354(1/2): 335-345.

[39] Kohler J, Caravaca F, Carrasco L, Roldán A. Interactions between a plant growth-promoting rhizobacterium, an AM fungus and a phosphatesolubilising fungus in the rhizosphere of Lactuca sativa. Applied Soil Ecology, 2007, 35(3) : 480-487.

[40] Lioussanne L, Jolicoeur M, St-Arnaud M. Mycorrhizal colonization with Glomus intraradices and development stage of transformed tomato roots significantly modify the chemotactic response of zoospores of the pathogen Phytophthora nicotianae. Soil Biology and Biochemistry, 2008, 40(9) : 2217-2224. 
[41] Chandanie W A, Kubota M, Hyakumachi M. Interactions between the arbuscular mycorrhizal fungus Glomus mosseae and plant growth-promoting fungi and their significance for enhancing plant growth and suppressing damping-off of cucumber (Cucumis sativus L.). Applied Soil Ecology, $2009,41(3): 336-341$.

[42] Liu R J, Dai M, Wu X, Li M, Liu X Z. Suppression of the root-knot nematode [Meloidogyne incognita ( Kofoid \& White) Chitwood] on tomato by dual inoculation with arbuscular mycorrhizal fungi and plant growth-promoting rhizobacteria. Mycorrhiza, 2012, 22 (4) : $289-296$.

[43] Vigo C, Norman J R, Hooker J E. Biocontrol of the pathogen Phytophthora parasitica by arbuscular mycorrhizal fungi is a consequence of effects on infection loci. Plant Pathology, 2000, 49(4) : 509-514.

[44] Whipps J M. Prospects and limitations for mycorrhizas in biocontrol of root pathogens. Canadian Journal of Botany, 2004 , 82( 8) : $1198-1227$.

[45] Tabin T, Arunachalam A, Shrivastava K, Arunachalam K. Effect of arbuscular mycorrhizal fungi on damping-off disease in Aquilaria agallocha Roxb. Seedlings. Tropical Ecology, 2009, 50(2) : 243-248.

[46] Francl L J, Dropkin V H. Glomus fasciculatum, a weak pathogen of Heterodera glycines. Journal of Nematology, 1985, 17 (4) : 470-475.

[47] Li X Z, Liu R, Qin Z L. Discovery of vesicular-arbuscular mycorrhizal fungi colonized in Heterodera glycines in China. Acta Pedologica Sinica, 1994, 31(S1): 230-233.

[48] Eissenstat D M, Graham J H, Syvertsen J P, Drouillard D L. Carbon economy of sour orange in relation to mycorrhizal colonization and phosphprus status. Annals of Botany, 1993, 71(1): 1-10.

[49] Smith S E, Jakobssen I, Grønlund M, Smith F A. Roles of arbuscular mycorrhizas in plant phosphorus nutrition: interactions between pathways of phosphorus uptake in arbuscular mycorrhizal roots have important implications for understanding and manipulating plant phosphorus acquisition. Plant Physiology, 2011, 156(3) : 1050-1057.

[50] Harrier L A, Watson C A. The potential role of arbuscular mycorrhizal ( AM) fungi in the bioprotection of plants against soil-borne pathogens in organic and/or other sustainable farming systems. Pest Management Science, 2004, 60(2) : 149-157.

[51] El-Khallal S M. Induction and modulation of resistance in tomato plants against Fusarium wilt disease by bioagent fungi ( arbuscular mycorrhiza) and/ or hormonal elicitors (jasmine acid \& salicylic acid) : 1-changes in growth, some metabolic activities and endogenous hormones related to defence mechanism. Australian Journal of Basic and Applied Sciences, 2007, 1(4) : 691-705.

[52] Castillo P, Nico A I, Azcón-Aguilar C, Del Río Rincón C, Calvet C, Jiménez-Díaz R M. Protection of olive planting stocks against parasitism of root-knot nematodes by arbuscular mycorrhizal fungi. Plant Pathology, 2006, 55(5) : 705-713.

[53] Hause B, Mrosk C, Isayenkov S, Strack D. Jasmonates in arbuscular mycorrhizal interactions. Phytochemistry, 2007, 68(1): 101-110.

[54] He Z Q, Li H X, Tang H R. Effect of arbuscular mycorrhizal fungi on endogenous in Cucumber after Rhizoctonia solani inoculation. Chinese Agricultural Science Bulletin, 2010, 26(17) : 187-190.

[55] Ortu G, Balestrini R, Pereira P A, Becker J D, Küster H, Bonfante P. Plant genes related to gibberellin biosynthesis and signaling are differentially regulated during the early stages of AM fungal interactions. Molecular Plant, 2012, 5(4) : 951-954.

[56] Dugassa G D, Vonalten H, Schonbeck F. Effects of arbuscular mycorrhizal ( AM) on health of linumusita tissimuml infected by fungal pathogens. Plant and Soil, 1996, 185(2): 173-182.

[57] Glazebrook J. Contrasting mechanisms of defense against biotrophic and necrotrophic pathogens. Annual Review of Phytopathology, 2005, 43( 1) : 205-227.

[58] Calcagno C, Novero M, Genre A, Bonfante P, Lanfranco L. The exudate from an arbuscular mycorrhizal fungus induces nitric oxide accumulation in Medicago truncatula roots. Mycorrhiza, 2012, 22(4): 259-269.

[59] Besson-Bard A, Pugin A, Wendehenne D. New insights into nitric oxide signaling in plants. Annual Review of Plant Biology, 2008, 59( 1) : 2l-39.

[60] Kapoor R. Induced resistance in mycorrhizal tomato is correlated to concentration of jasmonic acid. Online Journal of Biological Sciences, 2008, 8 (3) : 49-56.

[61] Jalali B L, Bhargava S, Kamble A. Signal transduction and transcriptional regulation of plant defence responses. Journal of Phytopathology, 2006, $154(2): 65-74$.

[62] Riedel T, Groten K, Baldwin I T. Symbiosis between Nicotiana attenuata and Glomus intraradices: ethylene plays a role, jasmonic acid does not. Plant, Cell and Environment, 2008, 31(9): 1203-1213.

[63] Li H Y, Liu R J, Shu H R, Li Y. Chib1 and PAL5 directly involved in the defense responses induced by the arbuscular mycorrhizal fungus Glomus fasciculatus against nematode. Mycosystema, 2005, 24(3) : 385-393.

[64] Liu J Y, Maldonado-Mendoza I, Lopez-Meyer M, Cheung F C, Town C D, Harrison M J. Arbuscular mycorrhizal symbiosis is accompanied by local and systemic alterations in gene expression and an increase in disease resistance in the shoots. The Plant Journal, 2007, 50(3): 529-544.

[65] Tahiri-Alaoui A, Frigotto L, Manville N, Ibrahim J, Romby P, James W. High affinity nucleic acid aptamers for streptavidin incorporated into bispecific capture ligands. Nucleic Acids Research, 2002, 30(10): 30-45.

[66] Gallou A, Mosquera H P L, Cranenbrouck S, Suárezb J P, Declerck S. Mycorrhiza induced resistance in potato plantlets challenged by Phytophthora infestans. Physiological and Molecular Plant Pathology, 2011, 76(1) : 20-26. 
[67] Isayenkov S, Mrosk C, Stenzel I, Strack D, Hause B. Suppression of allene oxide cyclase in hairy roots of Medicago truncatula reduces jasmonate levels and the degree of mycorrhization with Glomus intraradices. Plant Physiology, 2005, 139(3) : 1401-1410.

[68] Fester T, Hause G. Accumulation of reactive oxygen species in arbuscular mycorrhizal roots. Mycorrhiza, 2005, 15(5) : $373-379$.

[69] de Román M, Fernández I, Wyatt T, Sahrawy M, Heil M, Poze M J. Elicitation of foliar resistance mechanisms transiently impairs root association with arbuscular mycorrhizal fungi. Journal of Ecology, 2011, 99(1): 36-45.

[70] Schwarz D, Welter S, George E, Franken P, Lehmann K, Weckwerth W, Dölle S, Worm M. Impact of arbuscular mycorrhizal fungi on the allergenic potential of tomato. Mycorrhiza, 2011, 21(5) : 341-349.

[71] Kloppholz S, Kuhn H, Requena N. A secreted fungal effector of Glomus intraradices promotes symbiotic biotrophy. Current Biology, 2011, 21 (14) : 1204-1209.

\section{参考文献：}

[ 8 ] 卢金䔗, 杜茜, 间永利, 马琨, 王占军, 蒋齐. 盐渍化土壤根际微生物群落及土壤因子对 AM 真菌的影响. 生态学报, 2012, 32(13)： 4071-4078.

[12］黄京华, 骆世明, 曾任森. 丛枝菌根菌诱导植物抗病的内在机制. 应用生态学报, 2003, 14(5): 819-822.

[15] 王倡宪, 李晓林, 秦岭, 王贵强, 周建朝, 杨慧民. 利用丛枝菌根真菌提高植物抗病性研究进展. 中国生物防治, 2007, 23(S1): 64-69.

[16] 李海燕, 刘润进, 束怀瑞. 丛枝菌根真菌提高植物抗病性的作用机制. 菌物系统, 2001, 20(3): 435-439.

[17] 刘润进, 陈应龙. 菌根学. 北京: 科学出版社, 2007.

[19］崔卫东, 龙宣杞, 侯新强, 杨蓉, 补娟, 罗明. 黄萎病原菌胁迫对丛枝菌根化棉花幼苗根部防御性酶及超微结构的影响. 新疆农业科学, 2009, 46(6) : 1235-1244.

[31] 补娟, 崔卫东, 罗明, 龙宣杞, 杨蓉. 接种丛枝菌根真菌对棉花生长和黄萎病的影响. 新疆农业科学, 2009, 46(3): 549-555.

[47] 李杏忠, 刘润进, 秦志林. VAM 真菌定殖于大豆胞囊线虫在我国发现. 土壤学报, 1994, 31(S1): 230- 233.

［54］贺忠群, 李焕秀, 汤浩茹. 立枯丝核菌侵染下 AMF 对黄瓜内源激素的影响. 中国农学通报, 2010, 26(17)：187-190. 


\section{ACTA ECOLOGICA SINICA Vol.33, No.19 Oct.,2013(Semimonthly) CONTENTS}

A review of ecosystem services and research perspectives

MA Fengjiao,LIU Jintong, A. Egrinya Eneji (5963)

Sexual interference in non-human primates

YANG Bin, WANG Chengliang, JI Weihong, et al (5973)

Density-dependent effect on reproduction of rodents : a review …............. HAN Qunhua, GUO Cong, ZHANG Meiwen (5981)

Proximate and ultimate determinants of food chain length ............................ WANG Yuyu, XU Jun, LEI Guangchun (5990)

Mechanism of biological control to plant diseases using arbuscular mycorrhizal fungi

LUO Qiaoyu, WANG Xiaojuan, LI Yuanyuan, et al (5997)

Advances in effects of conservation tillage on soil organic carbon and nitrogen

XUE Jianfu, ZHAO Xin, Shadrack Batsile Dikgwatlhe, et al (6006)

Habitat selection of the pre-released giant panda in Wolong Nature Reserve

ZHANG Mingchun, HUANG Yan, LI Desheng, et al (6014)

Activity rhythm and behavioral time budgets of wild Reeves's Pheasant (Syrmaticus reevesii) using infrared camera …................

ZHAO Yuze, WANG Zhichen, XU Jiliang, et al (6021)

The energy budget of tree sparrows Passer montanus in wind different speed and duration

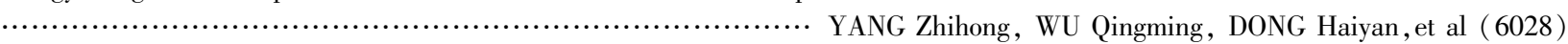

Nest site characteristics of Petaurista caniceps in Baima Snow Mountain Nature Reserve

LI Yanhong, GUAN Jinke, LI Dayong, HU Jie (6035)

Effects of habitat fragmentation on the genetic diversity of Pachycondyla luteipes on islands in the Thousand Island Lake, East

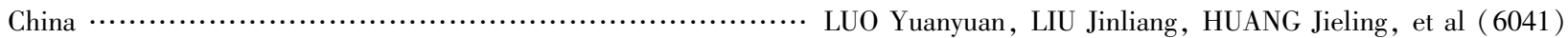

The molecular genetic relationship between the pollinators of Ficus pumila var. pumila and Ficus pumila var. awkeotsang ..............

WU Wenshan, CHEN Youling, SUN Lingli, et al (6049)

The genetic evolutionary relationships of two Eupristina species on Ficus altissima

............................................................ CHEN Youling, SUN Lingli, WU Leilei, et al (6058)

Metal uptake and root morphological changes for two varieties of Salix integra under cadmium stress

WANG Shufeng, SHI Xiang, SUN Haijing, et al (6065)

Effects of phthalic acid on seed germination, membrane lipid peroxidation and osmoregulation substance of radish seedlings ......................................................... YANG Yanjie, WANG Xiaowei, ZHAO Kang, et al (6074)

The morphological and physiological responses of Tamarix ramosissima seedling to different irrigation methods in the extremely arid area

MA Xiaodong, WANG Minghui, LI Weihong, et al (6081)

Response characteristics of photosynthetic and physiological parameters in Ziziphus jujuba var. spinosus seedling leaves to soil

water in sand habitat formed from seashells …................. WANG Rongrong, XIA Jiangbao, YANG Jihua, et al (6088)

Effects of ceramsite mulching on soil water content, photosynthetic physiological characteristics and growth of plants …...............

TAN Xuehong, GUO Xiaoping, ZHAO Tingning (6097)

Dynamics of tannin concentration and nutrient resorption for branchlets of Casuarina equisetifolia plantations at different ages .........

YE Gongfu, ZHANG Shangju, ZHANG Lihua, et al (6107)

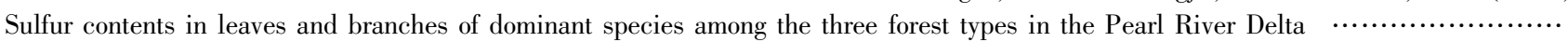

PEI Nancai, CHEN Bufeng, ZOU Zhijin, et al (6114)

Impacts of arbuscular mycorrhizal fungi and phosphorus on growth dynamics of Bauhinia faberi seedlings

SONG Chengjun, QU Laiye, MA Keming, et al (6121)

Characteristics of ion accumulation and seed germination for seeds from plants cultured at different concentrations of nitrate nitrogen and salinity

ZHOU Jiachao, FU Tingting, ZHAO Weiwei, et al (6129)

Physio-ecological effects of endophyte infection on the host grass with elevated $\mathrm{CO}_{2}$

Effects of pretreatment on germination of Typha domingensis and Phragmites australis

SHI Zhibing, ZHOU Yong, LI Xia, et al (6135)

MENG Huan, WANG Xuehong, TONG Shouzheng, et al (6142)

Transfer characteristics of cadmium from soil to Salix $\times$ aureo-pendula ….. ZHANG Wen, WEI Hong, SUN Xiaocan, et al (6147) Effect of Close-to-Nature management on the natural regeneration and species diversity in a masson pine plantation

LUO Yinghua, SUN Dongjing, LIN Jianyong, et al (6154)

Population dynamics and seed banks of the threatened seagrass Halophila beccarii in Pearl Bay, Guangxi

QIU Guanglong, FAN Hangqing, LI Zongshan, et al (6163)

Effects of biological crusts on dew deposition and evaporation in the Southern Edge of the Mu Us Sandy Land, Northern China ...... , Z

Life history characteristics and spatial distribution of Populus pruinosa population at the upper reaches of Tarim River $\cdots . . . . . . . . . . .$. .

Interactive effects of short-term nitrogen enrichment and simulated grazing on ecosystem respiration in an alpine meadow on the Tibetan Plateau ZONG Ning, SHI Peili, JIANG Jing, et al (6191) 
The correlation between soil water salinity and plant community distribution under micro-topography in Songnen Plain , W

Comparison of TSP, $\mathrm{PM}_{2.5}$ and their water-soluble ions from both inside and outside of Dafushan forest park in Guangzhou

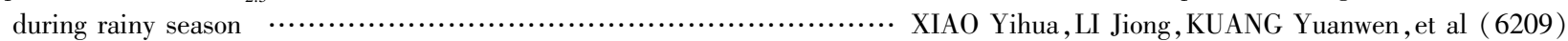

Fish community ecology in rocky reef habitat of $\mathrm{Ma}^{\prime}$ an Archipelago II . Spatio-temporal patterns of community structure

WANG Zhenhua, ZHAO Jing, WANG Kai, et al (6218)

Interannual variation in the population dynamics of snailfish Liparis tanakae in the Yellow Sea

CHEN Yunlong, SHAN Xiujuan, ZHOU Zhipeng, et al (6227)

Spatial and temporal variation of soil macro-fauna community structure in three temperate forests

... LI Na, ZHANG Xueping, ZHANG Limin (6236)

Community structure and species biodiversity of fig wasps in syconia of Ficus superba Miq. var. japonica Miq. in Fuzhou

CHEN Youling, CHEN Xiaoqian, WU Wenshan, et al (6246)

Marine ecological capital: valuation methods of marine ecosystem services …. CHEN Shang, REN Dachuan, XIA Tao, et al (6254)

Geomorphologic regionalization of China aimed at construction of nature reserve system ….......... GUO Ziliang, CUI Guofa (6264)

Impact of ecological vegetation construction on the landscape pattern of a Loess Plateau Watershed ....

YI Yang, XIN Zhongbao, QIN Yunbin, et al (6277)

Spatial heterogeneity of soil moisture across a cropland-grassland mosaic: a case study for agro-pastural transition in north of Chin

WANG Hongmei, WANG Zhongliang, WANG Kun, et al (6287)

The regional diversity of changes in growing duration of spring wheat and its correlation with climatic adaptation in Northern

China

Response of soil physical-chemical properties to rocky desertification succession in South China Karst ................................

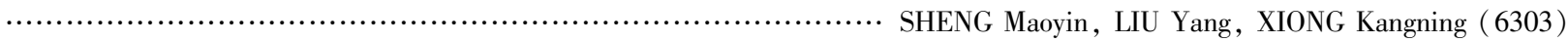

Prediction of the effects of climate change on the potential distribution of mire in Northeastern China

HE Wei, BU Rencang, LIU Hongjuan, et al (6314)

Soil nitrogen mineralization and associated temperature sensitivity of different Inner Mongolian grasslands

ZHU Jianxing, WANG Qiufeng, HE Nianpeng, et al (6320)

Effects of land use on soil nutrient in oasis-desert ecotone in the middle reach of the Heihe River

MA Zhimin, LÜ Yihe, SUN Feixiang, et al (6328)

Assessment on heavy metal pollution status in paddy soils in the northern Chengdu Plain and their potential ecological risk

QIN Yusheng, YU Hua, FENG Wenqiang, et al (6335)

Relationship between the temporal-spatial distribution of longline fishing grounds of yellowfin tuna (Thunnus albacares) and the thermocline characteristics in the Central Atlantic Ocean …......... YANG Shenglong, MA Junjie,ZHANG Yu, et al (6345)

Biological nitrogen fixation in the upper water column in the south Taiwan Strait during summer 2011

torage and drivers of forests carbon on the Beichangshan Island of Miaodao Archipelago

LIN Feng, CHEN Min, YANG Weifeng, et al (6354)

SHI Honghua, WANG Xiaoli, WANG Ai, et al (6363)

Impact of changes in vegetation types on soil $\mathrm{C}$ mineralization and associated temperature sensitivity in the Changbai Mountain

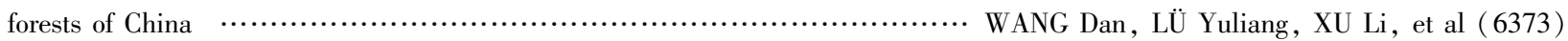

Analysis of relationship between genetic structure of Chinese Pine and mountain barriers

MENG Xiangxiang, DI Xiaoyan, WANG Mengben, et al (6382)

Soil organic carbon interpolation based on auxiliary environmental covariates:a case study at small watershed scale in Loess Hilly

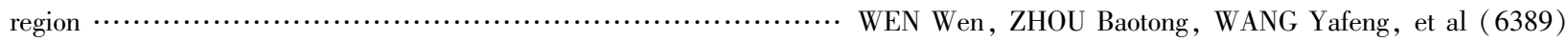

Eco-management benefit analysis of industrial resources from life cycle perspective: a case study of a virtual symbiosis network .

The game analysis between poverty and environment in ecologically fragile zones $\cdots$ QI Xinhua, YE Shilin, CHENG Yu, et al (6411)

The coupling development of economy and environment under the background of World Expo in Shanghai 


\section{《生态学报》2013 年征订启事}

《生态学报》是由中国科学技术协会主管, 中国生态学学会、中国科学院生态环境研究中心主办的生态学 高级专业学术期刊,创刊于 1981 年,报道生态学领域前沿理论和原始创新性研究成果。坚持“百花齐放,百家 争鸣” 的方针, 依靠和团结广大生态学科研工作者, 探索生态学奥秘, 为生态学基础理论研究搭建交流平台, 促进生态学研究深人发展, 为我国培养和造就生态学科研人才和知识创新服务、为国民经济建设和发展服务。

《生态学报》主要报道生态学及各分支学科的重要基础理论和应用研究的原始创新性科研成果。特别欢 迎能反映现代生态学发展方向的优秀综述性文章; 研究简报; 生态学新理论、新方法、新技术介绍; 新书评价和 学术、科研动态及开放实验室介绍等。

《生态学报》为半月刊,大 16 开本, 300 页, 国内定价 90 元/册, 全年定价 2160 元。

国内邮发代号: 82-7,国外邮发代号: M670

标准刊号:ISSN 1000-0933 CN 11-2031/Q

全国各地邮局均可订阅，也可直接与编辑部联系购买。欢迎广大科技工作者、科研单位、高等院校、图书 馆等订阅。

通讯地址: 100085 北京海淀区双清路 18 号 电话: (010)62941099; 62843362

E-mail: shengtaixuebao@ rcees.ac.cn网址: www.ecologica.cn

本期责任副主编 陈利顶 编辑部主任 孔红梅 执行编辑 刘天星 段 靖

\author{
生 态 学 报 \\ (SHENGTAI XUEBAO) \\ (半月刊 1981 年 3 月创刊)
}

第 33 卷 第 19 期 (2013 年 10 月)

\section{ACTA ECOLOGICA SINICA}

( Semimonthly, Started in 1981)

Vol. 33 No. 19 (October, 2013)

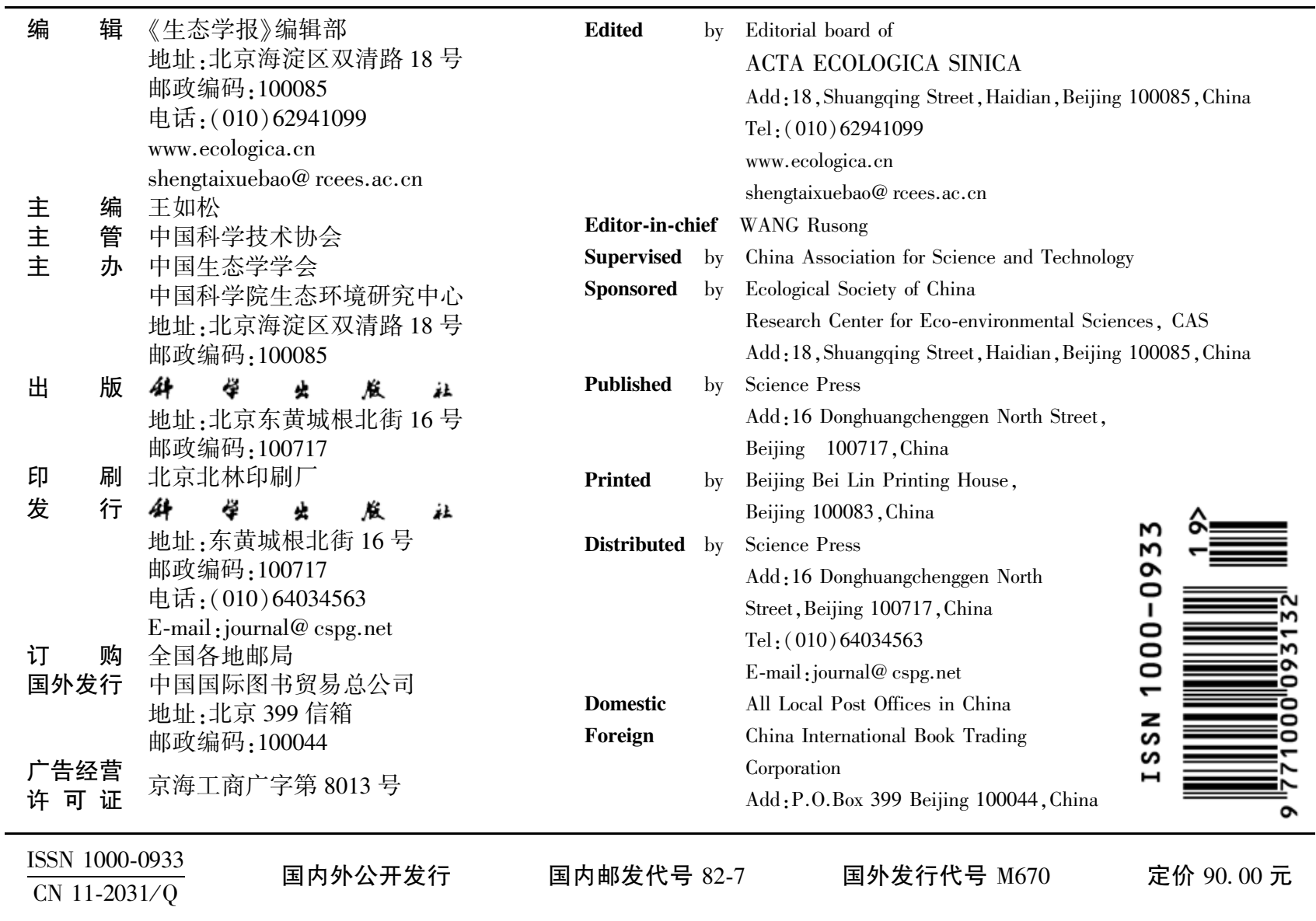

